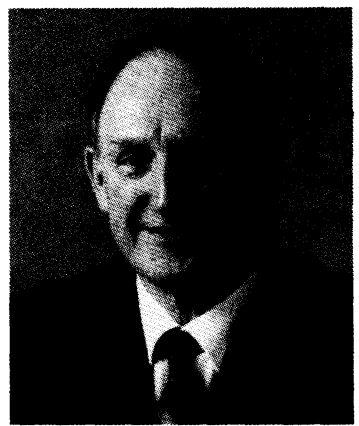

\section{University Libraries and Scholarly Communication}

The title of this editorial is the title of a study prepared for the Andrew W. Mellon Foundation by Cummings et al. ${ }^{1}$ This is a very important report that we should all read; but if nothing else, please read the foreword by William G. Bowen and the synopsis by Ann Okerson. I say we should all read it because the content should be of interest and the conclusions of concern to all readers of Optical Engineering.

Optical Engineering is committed to the communication of advances in optical science and engineering and is a scientific and technical archival publication that serves an international community. We sincerely hope that libraries will continue to carry this premiere journal in our field, or at least provide ready access to its contents to students and professional scientists and engineers. We do have the advantage, of course, of a very wide readership, with distribution to all our members. My own interest and concerns about the future of libraries, and particularly scholarly libraries, are multifaceted. Certainly, I have an interest from the point of view of Optical Engineering to make sure that the important information that it contains is widely disseminated. As many of you know, I also act as the series editor for the SPIE Milestone series, again a series that attempts, successfully I hope, to make available selected papers from the world's literature on various subdisciplines in our field. My work as the editor for a book series on optical engineering that began in 1982 and continues today, published by Marcel Dekker, is also important to me. Finally, I should add my other interest as the chair of the Editorial Board of the University of Rochester Press.

Having said all that, I then put on my other hat as Provost of the University of Rochester, a university with three major libraries. I worry each year about the budget for collections, how we can cope with the ever-increasing costs of publications, and how to change our point of view from one of collecting materials to one of providing access to materials, whether they are on our shelves, someone else's shelves, or only in the computer. For many years now we've been told that the electronic publishing age is here, yet books and journals still appear in hard copy. There is no doubt, however, that things are changing. Headlines pronounce "Publication by Electronic Mail Takes Physics by Storm"2 and "Libraries Shift From Books to Computers"3 to quote but two recent ones.

So back to the Mellon Foundation document report and my attempts to persuade readers of this editorial to read the report. The "principal findings or observations of the Mellon study" are listed in the synopsis that I mentioned earlier. Each finding or observation is highlighted and is followed by a short but meaningful discussion. I merely list the fifteen headings here:

1. Libraries have not taken a larger percentage of the university budget; their percentage has shrunk.

2. Materials and binding: These acquisitions-related expenditures have remained a remarkably constant percentage of total library expenditures as a whole, but make a significant reallocation between books and serials.

3. Books (nonserials): In the 1970 s and 1980 s, the rate of increase in volumes added at university research libraries virtually halted, while domestic and international publishing continued to produce greater and greater numbers of new titles each year.

4. Serials: Many speak of a "serials crisis" at the heart of library difficulties today, and it is prices, and in particular science journal prices, that drive the crisis.

5. Salaries as a percentage of total library expenditures have declined over the last two decades, while "other operating expenditures" (heavily reflecting computerization) have risen markedly.

6. The pressures described in the first part of this report will need to be addressed in many ways, but the possibilities of a significant increase in the role 
of electronic text distribution, maintenance, and use have the potential for being the most dramatic.

7. Until very recently, automation in libraries had addressed itself to existing internal functions (circulation, cataloging, and acquisitions), but the range of uses is becoming much broader.

8. At the present time, electronic publishing comprises many different kinds of information dissemination.

9. Scholarly publishing is closely tied to academic prestige, a link that exercises a conservative force on new arrangements.

10. Options for distribution of electronic texts are numerous and their costs at the present time uncertain.

11. Campus computing and telecommunications infrastructures will need to be upgraded to make the new technologies possible.

12. Traditional roles in the publishing process will undergo transformation.

13. Consistency of standards and of protocols has not yet been found.

14. Adaptation of current copyright practices to the new electronic environments poses numerous difficulties.
15. In the end, larger social issues will need to be addressed.

In conclusion, let me again stress the importance of the report and the importance of being involved in how we think about the library of the future. It is physically and financially impossible for the library of the future to be an expanded version of the library of today.

As an epilogue, I would also suggest some additional reading that came to my desk on the day I wrote this editorial. It is the second part of a two-part report by the Research Libraries Group titled "Preferred Library Futures II: Charting the Paths." 4

\section{References}

1. A. M. Cummings, M. L. Witte, W. G. Bowen, L. O. Lazarus, and R. H. Ekman, "University Libraries and Scholarly Communication," The Association of Research Libraries for the Andrew W. Mellon Foundation, p. 205 (1992).

2. "Publication by Electronic Mail Takes Physics by Storm," Science 259, 1246-1248 (February 1993).

3. "Libraries Shift From Books to Computers," publication unknown.

4. R. M. Dougherty and C. Huges, "Preferred Library Futures II: Charting the Paths," p. 27, The Research Libraries Group, Inc., Mountain View, CA (1993).

Brian J. Thompson Editor 
July 1993

Visual Communication and Image

Processing IV

Cheng-Tie Chen

Bellcore

445 South St.

Morristown, NJ 07962

201/829-5151 • 201/829-5884 FAX

Hsueh-Ming Hang

Center for Telecommunication Research

National Chiao-Tung University

Hsinchu, Taiwan

$+886 / 35-712121 \times 3298 \bullet+886 / 35-723283$

FAX

Kou-Hu Tzou

COMSAT Labs.

22300 Comsat Drive

Clarksburg, MD 20871

301/428-4663 • 301/428-7747 FAX

September 1993

Optical Science and Engineering in Canada

C.P. Grover

National Research Council

Institute for National Measurement Standards

Ottawa, Canada K1A OR6

613/993-2098 • 613/952-1394 FAX

\section{October 1993}

Microlithography

James R. Sheats

Hewlett-Packard Company

3500 Deer Creek Road

Palo Alto, CA 94304-1392

415/857-5987 • 415/857-2379 FAX

Optical Engineering in Hungary

Tivadar Lippenyi

HUNGOPTIKA

Tartsay u. 24

Budapest H-1120, Hungary

$3611563985 \cdot 3611563985$ FAX

Zoltan Fuzessy

Technical Univ. Budapest

Department of Physics

Balazs Bela u.36.IV.8.

Budapest $\mathrm{H}-1094$, Hungary

3611666361 • 3611666808 FAX

\section{November 1993}

Acquisition, Tracking, and Pointing

Mohammed A. Karim

University of Dayton

Center for Electro-Optics

300 College Park

Dayton, Ohio 45469-0227

$513 / 229-2241 \cdot 513 / 229-3433$

\section{December 1993}

Magnetospheric Imagery and

Atmospheric Remote Sensing

Supriya Chakrabarti

Boston University

Center for Space Physics

725 Commonwealth Avenue

Boston, MA 02215

E-mail: supc@bu-ast.bu.edu

617/353-5990 • 617/353-6463 FAX
January 1994

Infrared Technology

Marija S. Scholl

Alenlea Associates

P.O. Box 27408

Tempe, AZ 85285-7408

E-mail: msscholl@aol.com

602/491-7814

\section{February 1994}

Optical Interconnects and Packaging

Sing Lee

University of California/San Diego

E\&CE Department

La Jolla, CA 92093-0407

619/534-2413 • 619/534-1225 FAX

Manuscripts due July 1, 1993.

March 1994

High Heat Flux Optical Engineering

Ali M. Khounsary

Argonne National Laboratory

Advanced Photon Source, APS 362

Argonne, IL 60439

708/252-3384 • 708/252-3222 FAX

Manuscripts due Aug. 1, 1993.

April 1994

Optical Pattern Recognition

Joseph L. Horner

Rome Laboratory

EROP

Hanscom AFB, MA 01731-5000

617/377-3841 • 617/377-5041 FAX

Bahram Javidi

University of Connecticut

School of Engineering

Department of Electrical and Systems Engineering

Room 312, U-157

260 Glenbrook Road

Storrs, CT 06269-3157

203/486-4816 • 203/486-3789 FAX

Manuscripts due Sep. 1, 1993.

May 1994

Semiconductor Infrared Detectors

Antoni Rogalski

Military Technical Academy

Institute of Technical Physics

Kaliskiego St. 25

01-489 Warsaw 49, Poland

$4822369109 \cdot 4822362254$ FAX

Manuscripts due Oct. 1, 1993.

\section{June 1994}

Optical Science \& Engineering in India

Rajpal S. Sirohi

Indian Institute of Technology

Applied Optics Laboratory

Physics Department

Madras-600 036, India

044-2351365 ext. $221 \cdot 044-2350509$ FAX

Manuscripts due Nov. 1, 1993.
July 1994

Adaptive Wavelet Transforms

Harold H. Szu

U.S. Navy

Naval Surface Warfare Center

Code R44

10901 New Hampshire Avenue

Silver Springs, MD 20903-5000

301/394-3097 • 301/394-3923 FAX

Manuscripts due Dec. 1, 1993.

August 1994

Digital Image Recovery and Synthesis

Paul S. Idell

Air Force Phillips Lab.

PL/GPOA

390 B Great Road, \#18

Acton, MA 01720

612/377-3663 • 617/377-3661 FAX

Manuscripts due Dec. 1, 1993.

September 1994

Optics in South Africa

Hannes Markusse

ELOPTRO

Institute of Atomic Physics

P.O. Box 869

Kempton Park 1620, South Africa

Maurice W. McDowell

CSIR/Production Technology Div.

Productiontek

P.O. Box 395

Pretoria 0001, South Africa

$27128413418 \cdot 27128412131$ FAX

Manuscripts due Jan. 1, 1994.

October 1994

Optics in Russia

V. Ya. Panchenko

Scientific Research Center for Technological Lasers

Russia Academy of Sciences

B-333, Gubkina, 3

117971 Moscow, Russia

E-mail: ilc@compnet.npimsu.msk.su (095)135-54-30 • (095)334-02-01 FAX

Manuscripts due March 1, 1994.

November 1994

Micro-Optics

Chandrasekhar Roychoudhuri

University of Connecticut at Storrs

Photonics Research Center

MS-157, Room 312

260 Glenbrook Road

Storrs, CT 06269-3157

203/486-4816 • 203/486-3789 FAX

Manuscripts due April 1, 1994.

December 1994

Optics in Ireland

John Hegarty

C. D. Hussey

University of Dublin

Trinity College

Department of Pure and Applied Physics

Dublin 2, Ireland

+353-1-7022019 • +353-1-711759 FAX

Manuscripts due May 1, 1994. 